\title{
Self-reported oral health and quality of life in patients with type 2 diabetes mellitus in primary care: a multi-center cross-sectional study
}

This article was published in the following Dove Press journal: Diabetes, Metabolic Syndrome and Obesity: Targets and Therapy

\author{
Martijn JL Verhulst ${ }^{\prime}$ \\ Wijnand J Teeuw' \\ Victor EA Gerdes ${ }^{2,3}$ \\ Bruno G Loos' \\ 'Department of Periodontology, \\ Academic Centre for Dentistry \\ Amsterdam (ACTA), University of \\ Amsterdam and VU University, \\ Amsterdam, The Netherlands; \\ ${ }^{2}$ Department of Vascular Medicine, \\ Academic Medical Center (AMC), \\ University of Amsterdam, Amsterdam, \\ The Netherlands; ${ }^{3}$ Department of \\ Internal Medicine, Spaarne Gasthuis, \\ Hoofddorp, The Netherlands
}

Background: Guidelines for primary diabetes care recommend to pay attention to oral health in patients with diabetes mellitus type 2 (T2DM). However, research about dental care utilization and the extent of problems regarding oral health in these patients is limited.

Purpose: To assess self-reported oral health, general health-related quality of life (QoL) and oral health-related QoL in patients with T2DM who regularly attend a family physician office.

Methods: Family physician offices were recruited in the area of Amsterdam, the Netherlands, as part of a cluster-randomized controlled trial. At these offices, patients with T2DM were included by family physicians and/or nurse practitioners. Patient data on general characteristics, self-reported oral health (including periodontitis), general health-related QoL (SF-36) and oral health-related QoL (OHIP-NL14) were collected.

Results: Twenty-four family physician offices participated, who enrolled 764 patients with T2DM (mean age: $65.9 \pm 10.7$ years, $56 \%$ male, $16 \%$ smoker). Almost $11 \%$ of the patients were metabolically poorly controlled (HbA1c $>63 \mathrm{mmol} / \mathrm{mol}$ ), 39\% were obese (body mass index $\geq 30 \mathrm{~kg} / \mathrm{m}^{2}$ ), 37\% had hypertension (systolic blood pressure $\geq 140$ $\mathrm{mmHg}$ ) and $44 \%$ had dyslipidemia (LDL-cholesterol $>2.5 \mathrm{mmol} / \mathrm{L}$ ). About a quarter (24\%) reported not to visit a dentist regularly and 30\% did not have dental insurance coverage. Furthermore, $16 \%$ of the patients were edentulous and having full dental prostheses, while $29 \%$ had a partial dental prosthesis. Pain in the mouth, dry mouth and bad breath were reported by $15 \%, 37 \%$ and $12 \%$ of the patients, respectively. Almost $70 \%$ suffered from periodontitis. Oral health-related QoL was impaired in $19 \%$ of the patients, and those subjects also had worse general health-related QoL.

Conclusion: Almost a quarter of patients with T2DM at Dutch family physician offices does not visit the dentist regularly. The estimated prevalence of periodontitis is particularly high, but other oral health complaints and impaired oral health-related QoL are also relatively common.

Keywords: self-reported oral health, oral health-related quality of life, diabetes mellitus type 2 , primary care, family physician

\section{Introduction}

Diabetes mellitus (DM) is a chronic disease that affects approximately 422 million individuals, or $8.5 \%$ of the global population. ${ }^{1}$ Patients with DM are susceptible to develop microvascular and macrovascular complications, such as retinopathy, nephropathy, neuropathy and cardiovascular diseases. ${ }^{2}$ These complications are a major cause of morbidity in patients with DM, severely impairing quality of life (QoL). ${ }^{3,4}$
Department of Periodontology, Academic Centre for Dentistry Amsterdam (ACTA), University of Amsterdam and VU University, Amsterdam, The NetherlandsGustav Mahlerlaan 3004, Amsterdam, LA 108I, The Netherlands $\mathrm{Tel}+3 \quad 1205980173$

Email m.verhulst@acta.nl 
The oral cavity might be susceptible to the detrimental consequences of DM as well. ${ }^{5,6}$ Research has shown that DM is associated with several "oral complications". Especially the relationship with periodontitis is well established; not only is periodontitis considered a complication of $\mathrm{DM}^{7}$, recent research even showed that treatment of periodontitis is beneficial for the management of type 2 $\mathrm{DM}$ (T2DM) regarding $\mathrm{HbA}_{1 \mathrm{c}}$ levels, indicating a bidirectional association. ${ }^{8}$ However, other diseases and complaints - such as dry mouth, Candida infections and even oral cancer - are also more prevalent in patients with DM. ${ }^{9}$ It is likely that these complications will impair oral healthrelated QoL, as has been demonstrated in the case of, for example, periodontitis ${ }^{10}$ or dry mouth. ${ }^{11}$ Poor selfperceived oral health has also been associated with impaired general health-related QoL in patients with T2DM. ${ }^{12}$ For those reasons, more awareness for oral health in diabetes care is recommended by international organizations, such as the International Diabetes Federation ${ }^{13}$ and the American Diabetes Association. ${ }^{14}$

In the Netherlands, medical treatment for T2DM is organized in a structured program in primary care, with a central role for the family physician and nurse practitioner. As described in the care guidelines, its main focus is to prevent the development and progression of complications and comorbidities and thereby maintaining satisfactory QoL. ${ }^{15}$ Since 2013, oral health is also included in this guideline for the same purpose, considering the association between T2DM and several oral complications. However, oral health, general healthrelated QoL and oral health-related QoL have not been investigated in patients with T2DM attending the primary diabetes care program. Studies from the USA also demonstrated that patients with DM tend to visit the dentist less frequently, compared to subjects without DM. ${ }^{17-19}$ Insufficient dentist consultation is likely to result in poor oral health; ${ }^{20}$ however, recent figures about dental care utilization amongst patients with T2DM attending primary diabetes care are not available.

Insight into dental care utilization and the extent of perceived oral health problems of patients with T2DM will add perspective to the recommendations formulated in primary diabetes care guidelines. Therefore, this crosssectional study aims to assess self-reported oral health, dental care utilization and QoL (both general health- and oral health-related) in patients with T2DM at family physician offices.

\section{Materials and methods}

\section{Study design and protocol}

The present study is the first part of a cluster randomized controlled trial that investigates the implementation of oral care in primary diabetes care and its effect on patientcentered outcome parameters. The current report presents a cross-sectional baseline analysis of the study population. The design of the entire project is presented in Figure 1. The study was approved by the medical ethical committee of the Vrije Universiteit Medical Centre (2014.585) and registered at the ISRCTN registry (number: ISRCTN10145611).

First, family physician offices were recruited in order to include patients with T2DM that attended the primary care system. The target area was Amsterdam, the Netherlands, aiming at a total of 24 offices. Participating offices were randomly assigned to either the "experimental-office group" or "control-office group", using the sequentially numbered, opaque sealed envelopes (SNOSE) allocation protocol. ${ }^{21}$ In both "office groups", the family physicians and nurse practitioners were instructed to first screen their population and identify eligible subjects. The patient inclusion criteria were: 1) $\geq 18$ years; 2) diagnosed with T2DM; 3 ) follows the standardized primary care protocol, including an annual examination and 4) understands spoken and written Dutch. Patients included by GPs and nurse practitioners in both "office groups" represented the current study population for the cross-sectional baseline analysis. In the Netherlands, patients with T2DM are monitored at the family physician office every 3-6 months. ${ }^{15}$ During these consultation hours, as many patients with T2DM as possible were included, for an inclusion period of 12 months. Hence, theoretically, there were two to four inclusion opportunities for each patient.

The outcome measures were self-reported oral health and general and oral health-related QoL for which patients were followed up for approximately 1 year.

\section{Patient characteristics}

The electronic health records at the family physician offices provided patient characteristics and various parameters regarding general health and DM. For each parameter, the value closest to the inclusion date was extracted, with a maximum of 6 months before or after that date. Patient characteristics included age, sex, smoking status (yes or no), ethnicity (clustered in Western-European and other) and education level (stratified in: primary, secondary and higher). Furthermore, weight, body mass index (BMI) and blood pressure were extracted. $\mathrm{HbA}_{1 \mathrm{c}}$ levels 


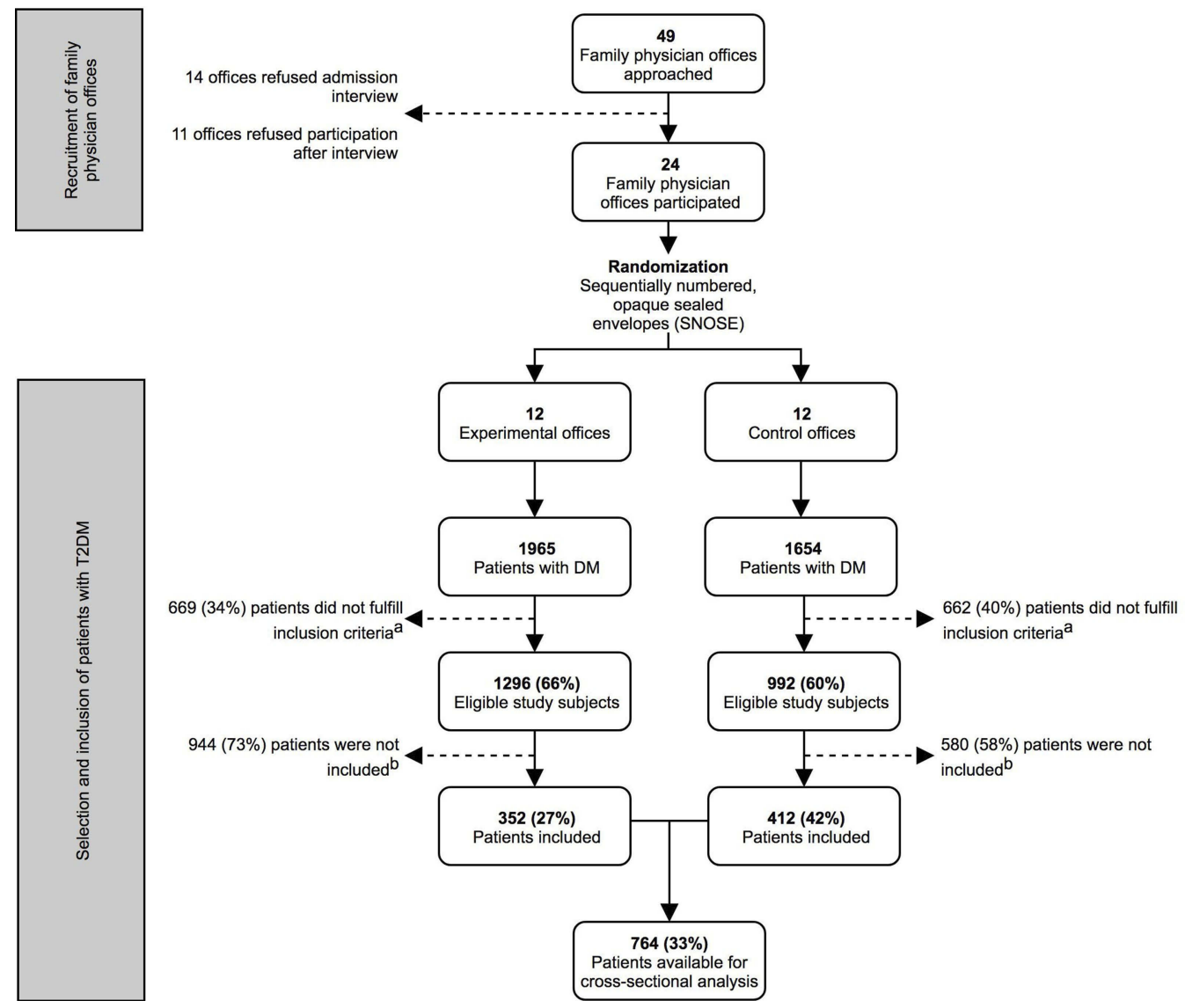

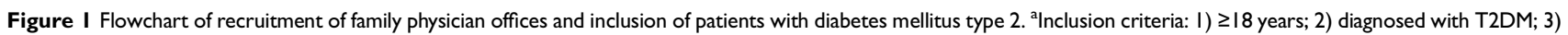
follows the standardized primary care protocol, including an annual examination; 4) understands spoken and written Dutch. ' Main reasons for not participating in the study: lack of time and routine of the nurse practitioners and/or family physicians; financial issues for certain patients; disinterest and lack of motivation of certain patients; dental anxiety.

were used to define metabolic control $(>53 \mathrm{mmol} / \mathrm{mol}$ and $>63 \mathrm{mmol} / \mathrm{mol}$ for moderate and poor control, respectively). A BMI $\geq 30 \mathrm{~kg} / \mathrm{m}^{2}$ indicated obesity; ${ }^{22}$ systolic blood pressure $\geq 140 \mathrm{mmHg}$ was classified as hypertension. ${ }^{23}$ Patients with low-density lipoprotein cholesterol (LDL-C) levels $>2.5 \mathrm{mmol} / \mathrm{L}$ were identified with dyslipidemia, as this is the cutoff value used by Dutch family physicians to commence statin therapy. ${ }^{24}$ Reduced kidney function was defined as an estimated glomerular filtration rate (eGFR) $<60 \mathrm{~mL} / \mathrm{min} / 1.73 \mathrm{~m}^{2}{ }^{25}$ The presence of retinopathy and the Simm's classification - which serves as a risk score for diabetic foot ${ }^{15}$ - were obtained from the electronic health record. The latter risk score ranges from 0 (no risk) to 1 (moderate risk: loss of sensibility or signs of peripheral artery disease), 2 (high risk: combination of loss of sensibility and/or peripheral artery disease and/or signs of locally increased pressure) and 3 (very high risk: presence of an ulcer or a history of amputation).

\section{Self-reported oral health measurement}

Self-reported oral health and dental care utilization were assessed by conducting a questionnaire. The first part of the questionnaire (Table S3) consisted of six questions developed for the current study. Dental care utilization was defined by three questions: did patients have a dentist, did they visit the dentist at least once per year, and did they have dental insurance coverage. Further, the participants were asked to estimate their number of teeth, and whether they were wearing a partial/full dental prosthesis. Complaints regarding oral health were assessed by asking patients whether they sometimes experienced pain in the mouth, dry mouth (ie, xerostomia) and/or bad breath.

The second part of the questionnaire (Table S4) consisted of eight questions originating from the studies from the USA, which strongly correlated with the presence of periodontitis. ${ }^{26,27}$ The questions were recently translated and validated in a Dutch cohort and developed into a screening 
tool. $^{28}$ This tool was able to accurately distinguish periodontitis patients, defined according to the golden standard, ie, full mouth clinical periodontal measurements. ${ }^{29}$

\section{General health-related qol}

To determine general health-related QoL, the validated Dutch version of the 36-item Short Form health survey (SF-36) was used. $^{30}$ Similar to the original version, this questionnaire consisted of 36 items, covering eight health concept scales: physical functioning, social functioning, role limitations due to physical health problems, role limitations due to emotional problems, general mental health, vitality, bodily pain and general health perceptions. Also, one item represented the perceived change in health over time. ${ }^{31}$ All responses were recoded to a linear $0-100$ scale, with a higher score indicating higher general health-related QoL.

\section{Oral health-related QoL}

Oral health-related QoL was determined using the validated Dutch version of the short-form Oral Health Impact Profile (OHIP-NL14), a self-administered questionnaire. ${ }^{32}$ Responses to the 14 items of the OHIP-NL14 were coded as follows: "never (0)", "hardly ever (1)", occasionally (2)", "fairly often (3)" and "very often (4)". A completed questionnaire resulted in seven conceptual subdomains scores (functional limitation, physical pain, psychological discomfort, physical disability, psychological disability, social disability and handicap) and a total score. ${ }^{33}$ Each subdomain yielded a severity score of the perceived impact, ranging from 0 to 8 , with higher scores indicating more impact in oral health-related QoL. Subsequently, the sum of these seven subdomains severity scores formed the total OHIPNL14 score, ranging from 0 to $56 .{ }^{33}$ In addition to these severity scores, the OHIP-NL14 could also determine the impact in oral health-related QoL. This was determined by dichotomizing the questions: a threshold of at least "occasionally" as a response was considered as an impact, "never" or "hardly ever" were considered as no impact. ${ }^{33}$ In this way, the prevalence of patients with an impact in oral healthrelated QoL - regarding both the subdomains and total score - could be determined. For determining both the severity scores and impact in oral health-related QoL, only complete questionnaires were used, those with one or more missing items were discarded from the final analysis.

\section{Statistical analysis}

Descriptive statistics (mean \pm standard deviations or numbers [\%] of subjects) were used to present patient characteristics, self-reported oral health, oral health-related QoL and general health-related QoL. Internal consistency of the OHIP-NL14 severity scores (total and subscales) and SF-36 concept scales were determined by calculating Cronbach's Alpha. Explorative analyses were performed to assess differences in self-reported oral health problems and oral health-related QoL between subpopulations. For comparing the prevalence of oral health problems and the impact in oral health-related QoL between subpopulations, chi-square tests were used. Differences in oral health-related QoL severity scores were assessed by Mann-Whitney U tests for comparison of two groups and Kruskal-Wallis tests for more than two groups. Considering the large number of comparisons, $p$-values $<0.01$ were considered significant. General health-related QoL was compared between patients with or without an impact in oral health-related QoL using Mann-Whitney U tests; general health-related QoL of our study population was compared to that of the general population of the Netherlands and a subgroup of inhabitants of the city of Amsterdam $^{30}$ using one-sample t-tests. For both analyses, $p$-values $<0.05$ were considered significant.

\section{Results \\ Study population}

Figure 1 presents a flowchart of the recruitment of family physician offices and subsequent selection and inclusion of patient with T2DM. Of 49 offices that were approached during the recruitment period (February 2015November 2015), a total of 24 family physician offices agreed to participate. The inclusion of patients with T2DM in the first participating office commenced in March 2015, and ended in September 2016, when the inclusion period of one year had ended for the last participating office. The total pool of patients with DM consisted of 3,619 individuals, of which 2,288 subjects were considered to be eligible after initial screening. A total of 764 patients $(33 \%)$ were finally included. The main reasons for not participating in the current study were: a lack of time and routine by the family physicians and/or nurse practitioners, financial issues for certain patients, disinterest, and lack of motivation of certain patients and dental anxiety.

General patient characteristics are presented in Table 1. The final study population's mean age was $65.9 \pm 10.7$ years, $55.8 \%$ of the patients were male and $15.8 \%$ were smoker. Almost $11 \%$ were poorly controlled $\left(\mathrm{HbA}_{1 \mathrm{c}}>63\right.$ $\mathrm{mmol} / \mathrm{mol}$ ), $40 \%$ of the participants were obese (BMI $\geq 30 \mathrm{~kg} / \mathrm{m}^{2}$ ), $37 \%$ had hypertension (systolic blood 
Table I Patient characteristics (total study population, $n=764$ )

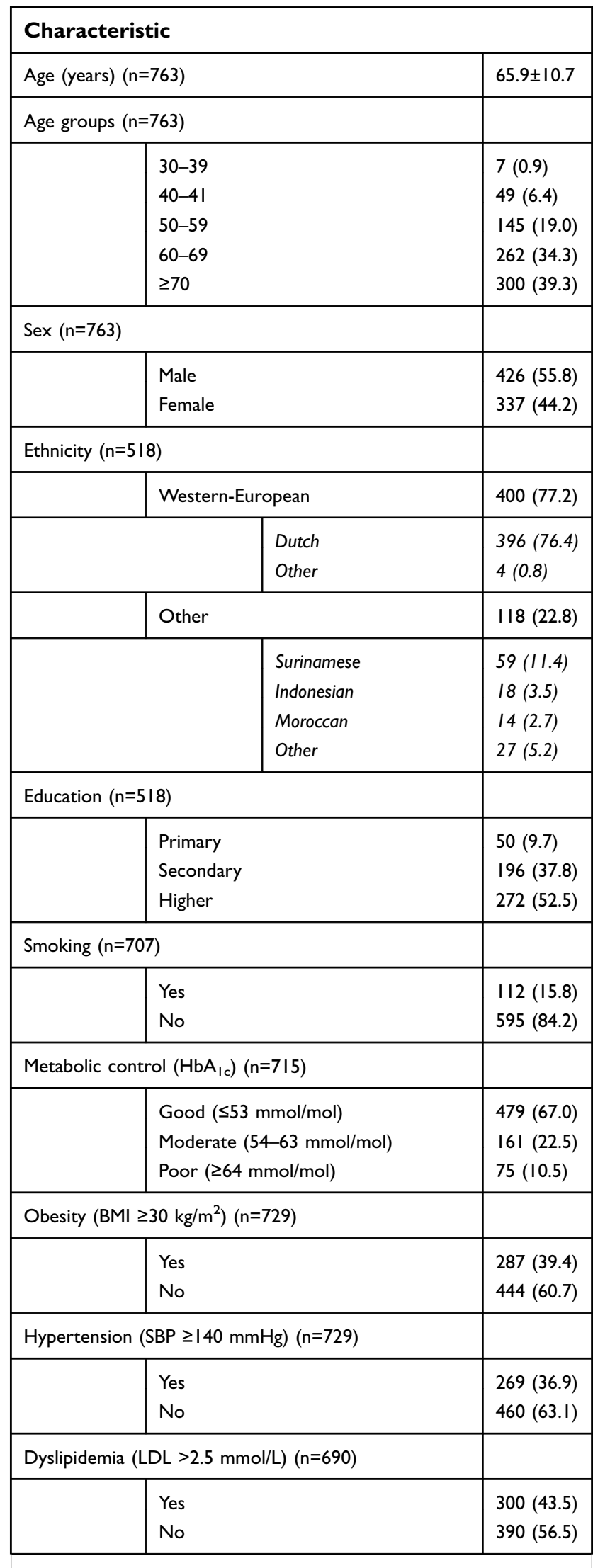

(Continued)
Table I (Continued).

\begin{tabular}{|l|l|l|}
\hline \multicolumn{2}{|l|}{ Characteristic } \\
\hline \multicolumn{2}{|l|}{ Kidney dysfunction (eGFR $\left.<60 \mathrm{~mL} / \mathrm{min} / \mathrm{I} .73 \mathrm{~m}^{2}\right)(\mathrm{n}=682)$} & \\
\hline & Yes & $142(20.8)$ \\
& No & $(79.2)$ \\
\hline Retinopathy (n=450) & \\
\hline & Yes & $18(4.0)$ \\
& No & $432(96.0)$ \\
\hline Diabetic foot risk (n=639) & \\
\hline \multicolumn{2}{|l|}{ None (Simm's 0) } & $457(71.5)$ \\
& Moderate (Simm's I) & $90(14.1)$ \\
& High (Simm's 2) & $(12.5)$ \\
& Very high (Simm's 3) & $12(1.9)$ \\
\hline
\end{tabular}

Notes: For each parameter, the number of subjects with available data is provided. Data are presented as mean \pm SD or $\mathrm{n}(\%)$. Note: When the $\mathrm{n}$ for a variable differs from the overall patient population, this is the result of missing data. Percentages represent only non-missing data.

Abbreviations: SPB, systolic blood pressure; LDL, low-density lipoprotein; eGFR, estimated glomerular filtration rate.

pressure $>140 \mathrm{mmHg}$ ) and $44 \%$ had dyslipidemia (LDLcholesterol $>2.5 \mathrm{mmol} / \mathrm{L}$ ). Kidney dysfunction (eGFR $<60 \mathrm{~mL} / \mathrm{min} / 1.73 \mathrm{~m}^{2}$ ) was observed in $21 \%$ of the subjects. Retinopathy was present in $4 \%$ of the population, while $28.5 \%$ had an increased risk score for diabetic foot.

\section{Self-reported oral health}

The self-reported oral health questionnaire was - at least partly - answered by all 764 patients (Tables 2 and 3). The first part of the questionnaire (presented in Table 2) revealed that $76 \%$ of the patients visited a dentist regularly (at least once a year). In individuals aged $\leq 65$ years, this was $83 \%$, decreasing to $71 \%$ in subjects older than 65 years $(p<0.001)$. Fewer edentulous patients visited the dentist regularly (29\%), compared to dentate subjects $(85 \%, p<0.001)$. This was also the case for smokers $(67 \%)$ in comparison to non-smokers $(78 \%$, $p=0.012$ ). Furthermore, $84 \%$ of the patients had a dentist, while $69 \%$ had dental insurance coverage. Of all participants, $16 \%$ was edentulous and full dental prosthesis wearers, while $29 \%$ had a partial dental prosthesis. Edentulousness was more prevalent in older individuals $(p<0.001)$, as well as in patients with WesternEuropean ethnicity ( $16 \%$ vs $6 \%$ in other, $p=0.007)$, hypertension ( $20 \%$ vs $14 \%$ in normotensive, $p=0.018$ ) and reduced kidney function $(30 \%$ vs $13 \%$ in normal function, $p<0.001$ ) (Table S1). 
Table 2 Self-reported oral health: dental care utilization and oral health complaints $(n=764)$



Notes: Data are presented as $\mathrm{n}(\%)$. When the $\mathrm{n}$ for a variable differs from the overall patient population, this is the result of missing data. Percentages represent only non-missing data.

Complaints of pain in the mouth, xerostomia and bad breath were reported by $15 \%, 37 \%$ and $12 \%$ of the patients, respectively, while a total of $51 \%$ reported at least one of these complaints (Table 2). Xerostomia was observed more frequently in smokers (47\%) and individuals with obesity (43\%), compared to nonsmokers $(33 \%, p=0.004)$ and non-obese subjects $(32 \%$, $p=0.004$ ), respectively. Also, $46 \%$ of the patients with an increased risk score for diabetic foot (Simm's 1, 2 or 3) reported a dry mouth, compared to $32 \%$ for subjects without an increased risk (Simm's $0, p=0.001$ ). Pain in the mouth was reported more often by subjects with poor metabolic control (24\%), compared to patients with moderate $(11 \%)$ and $\operatorname{good}(14 \%)$ metabolic control $(p=0.033)$. Self-reported bad breath was more prevalent in individuals $<50$ years old (32\%), compared to patients aged 50-59 years $(15 \%), 60-69$ years $(12 \%)$ and $\geq 70$ years $(7 \%)$ $(p<0.001)$. Bad breath was also reported more frequently in patients with obesity $(15 \%)$ than in non-obese subjects $(10 \%, p=0.039)$ (Table S1).

The responses to the second part of the self-reported oral health questionnaire, containing periodontitis-related questions, are displayed in Table 3 . Of the dentate subjects, $69 \%$ were classified with periodontitis. In patients aged 30-39 years, the prevalence was $29 \%$, increasing to $66 \%$ in individuals aged $40-49$ years, $70 \%$ in those aged $50-59$ years, $76 \%$ in subjects aged $60-69$ and finally $64 \%$ in patients of 70 years or older $(p=0.016)$. Periodontitis was also observed more frequently in smokers (78\%) vs $67 \%$ in non-smokers $(p=0.036)$. Individuals without a dentist were also classified with periodontitis more often $(83 \%)$, compared to those with a dentist $(68 \%$, $p=0.024$ ). (Table $\mathrm{S} 1$ ). When including periodontitis to the list of self-reported oral health problems (pain in the mouth, dry mouth, bad breath), $82 \%$ of all subjects was suffering from at least one of those problems.

\section{General health-related QoL}

The SF-36 questionnaire was completed by 544 (71\%) subjects (Table 4). The internal consistencies of the conceptual scales (Cronbach's Alpha) were: 0.919 (physical functioning), 0.763 (social functioning), 0.887 (role limitations due to physical health problems), 0.855 (role limitations due to emotional problems), 0.845 (general mental health), 0.767 (vitality), 0.852 (bodily pain) and 0.734 (general health perceptions). Since the last scale "changes in health over time" was composed by only one question, internal consistency was not calculated. The concept scale scores ranged from 52.7 (changes in health over time) to 81.1 (social functioning). All concept scale scores were significantly lower compared to the general Dutch population, ${ }^{30}$ except for general mental health and bodily pain (Table 4), indicating impaired general health-related QoL. 
Table 3 Self-reported oral health: periodontitis related items (only dentate subjects; $n=636$ )

\begin{tabular}{|c|c|c|}
\hline \multicolumn{2}{|l|}{ Question } & n (\%) \\
\hline \multicolumn{3}{|c|}{ Do you think you might have gum disease? $(n=589)$} \\
\hline & Yes & $118(20.0)$ \\
\hline & No & $47 I(80.0)$ \\
\hline \multicolumn{3}{|c|}{$\begin{array}{l}\text { Overall, how would you rate the health of your teeth } \\
\text { and gums? }(n=628)\end{array}$} \\
\hline & Poor & $31(4.9)$ \\
\hline & Fair & $199(31.7)$ \\
\hline & Good & $320(51.0)$ \\
\hline & Very good & $59(9.4)$ \\
\hline & Excellent & $19(3.0)$ \\
\hline \multicolumn{2}{|c|}{$\begin{array}{l}\text { Have you ever had treatment for gum disease such as } \\
\text { scaling and root planing, sometimes called "deep clean- } \\
\text { ing"? }(n=606)\end{array}$} & \\
\hline & Yes & $188(31.0)$ \\
\hline & No & $418(69.0)$ \\
\hline \multicolumn{3}{|c|}{$\begin{array}{l}\text { Have you ever had any teeth become loose on their } \\
\text { own, without an injury? }(n=628)\end{array}$} \\
\hline & Yes & III (17.7) \\
\hline & No & $517(82.3)$ \\
\hline \multicolumn{3}{|c|}{$\begin{array}{l}\text { Have you ever been told by a dental professional that } \\
\text { you lost bone around your teeth? }(n=6 \mid 2)\end{array}$} \\
\hline & Yes & $69(11.3)$ \\
\hline & No & $543(88.7)$ \\
\hline \multicolumn{3}{|c|}{$\begin{array}{l}\text { During the past } 3 \text { months, have you noticed a tooth that } \\
\text { does not look right? }(n=623)\end{array}$} \\
\hline & Yes & $50(8.0)$ \\
\hline & No & $573(92.0)$ \\
\hline \multicolumn{2}{|c|}{$\begin{array}{l}\text { Aside from brushing your teeth with a toothbrush, in } \\
\text { the last } 7 \text { days, how many times did you use dental floss } \\
\text { or any other device to clean between your teeth? } \\
(n=626)\end{array}$} & \\
\hline & I-7 days & $482(77.0)$ \\
\hline & Never & $144(23.0)$ \\
\hline \multicolumn{2}{|c|}{$\begin{array}{l}\text { Aside from brushing your teeth with a toothbrush, in } \\
\text { the last } 7 \text { days, how many times did you use mouthwash } \\
\text { or other dental rinse product that you use to treat } \\
\text { dental disease or dental problems? }(n=626)\end{array}$} & \\
\hline & I-7 days & $227(36.3)$ \\
\hline & Never & $399(63.7)$ \\
\hline \multicolumn{2}{|c|}{ Periodontitis screening tool } & \\
\hline Periodontitis* & & \\
\hline
\end{tabular}

(Continued)
Table 3 (Continued).

\begin{tabular}{|l|l|l|}
\hline \multicolumn{2}{|l|}{ Question } & n (\%) \\
\hline & Yes & $407(69.3)$ \\
& No & $180(30.7)$ \\
\hline
\end{tabular}

Notes: Data are presented as $\mathrm{n}(\%)$. Note: When the $\mathrm{n}$ for a variable differs from the overall patient population, this is the result of missing data. Percentages represent only non-missing data. The questions presented here are the original questions developed by Eke et al. ${ }^{26}$ The Dutch translations can be found in Appendix 2. *Estimated by applying screening tool. ${ }^{28}$

\section{Oral health-related QoL}

The OHIP-NL14 was completed by $640(84 \%)$ subjects (Table 5). Internal consistency of the total OHIP-NL14 severity score was high (Cronbach's Alpha $=0.915)$. For the subscale scores, these were: 0.675 (functional limitation), 0.717 (physical pain), 0.861 (psychological discomfort), 0.754 (physical disability), 0.742 (psychological disability), 0.688 (social disability) and 0.597 (handicap). Of the 640 patients who completed the OHIP-NL14 questionnaire, $19 \%$ reported at least some impact (score of 2 ["occasionally"] or higher) in one or more subdomain (Table 5). The mean total OHIP-NL 14 score was $2.5 \pm 5.2$. Of the seven subdomains, physical pain was the most frequently mentioned impairment, with $12.0 \%$ of the population reporting some impact. The other subdomains were less frequently mentioned, as the impact prevalence ranged from $2.8 \%$ to $6.9 \%$. A total score of $0-$ indicating no impairment in oral health-related QoL at all was observed in 345 patients (53.9\%).

Oral health-related QoL was impaired by pain in the mouth, xerostomia and bad breath, as shown in Table 6 . Patients with periodontitis also had worse oral health-related QoL, with a mean score of $2.6 \pm 4.7$ and an impact in $22 \%$ of the cases, compared to a mean score of $0.8 \pm 3.4$ and an impact prevalence of $6 \%$ in patients without periodontitis ( $p<0.001$ for both measures) (Table 6). Finally, oral health-related QoL was lower in edentulous patients, with a mean OHIP-NL14 score of $3.6 \pm 7.0$, compared to $2.3 \pm 4.8$ in dentate subjects $(p=0.024)$.

The prevalence of an impact in oral health-related QoL was lower in patients with Western-European ethnicity (15\%), compared to patients of another ethnicity $(27 \%$, $p=0.003)$. Smokers also reported an impact in oral healthrelated QoL more frequently $(29 \%$ vs $17 \%$ in nonsmokers, $p=0.007)$ and showed a worse mean OHIP-NL 14 score ( $3.8 \pm 6.1$ vs $2.2 \pm 4.5$ in non-smokers, $p=0.003$ ). Oral health-related QoL was also impaired in patients with low dental care utilization. For example, a mean OHIP-NL 14 score of $3.6 \pm 6.3$ was found in individuals without 
Table 4 General health-related QoL (SF-36) of the study population ( $n=544)$, and compared to the general population from the Netherlands $(n=1,742)$ and Amsterdam $(n=4,172)$

\begin{tabular}{|l|l|l|l|}
\hline SF-36 concept scales & Current study & $\begin{array}{l}\text { General population } \\
\text { the Netherlands }\end{array}$ & $\begin{array}{l}\text { General population } \\
\text { Amsterdam }\end{array}$ \\
\hline Physical functioning & $75.0 \pm 23.5$ & $83.0 \pm 22.8^{* *}$ & $85.2 \pm 23.1$ \\
Social functioning & $81.1 \pm 21.8$ & $84.0 \pm 22.4^{*}$ & $85.1 \pm 21.5$ \\
Role limitations due to physical health problems & $68.3 \pm 40.2$ & $76.4 \pm 36.3^{* *}$ & $79.5 \pm 35.4$ \\
Role limitations due to emotional problems & $77.7 \pm 36.5$ & $82.3 \pm 32.9 *$ & $83.1 \pm 32.7$ \\
General mental health & $76.0 \pm 18.5$ & $76.8 \pm 17.4$ & $75.9 \pm 17.6$ \\
Vitality & $64.8 \pm 19.8$ & $68.6 \pm 19.3^{* *}$ & $68.6 \pm 19.2$ \\
Bodily pain & $74.4 \pm 24.3$ & $74.9 \pm 23.4$ & $80.5 \pm 24.4$ \\
General health perceptions & $58.5 \pm 19.1$ & $70.7 \pm 20.7^{* *}$ & $71.3 \pm 20.8$ \\
Changes in health over time & $52.7 \pm 19.9$ & $\mathrm{n} / \mathrm{a}$ & $\mathrm{n} / \mathrm{a}$ \\
\hline
\end{tabular}

Notes: Data are presented as mean \pm SD. Concept scales according to Ware et al. ${ }^{31}$ abased on 544 participants that have filled in the SF-36 questionnaire completely.

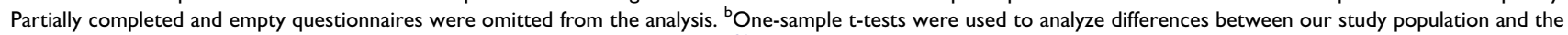
general population from the Netherlands $(n=I, 742)$ and Amsterdam $(n=4,172) .{ }^{30} * p<0.01, * * p<0.00$ I

Table 5 Oral health-related QoL (OHIP-NLI4) $(n=640)$

\begin{tabular}{|l|l|l|}
\hline $\begin{array}{l}\text { OHIP-NLI4 } \\
\text { subdomain }^{\mathbf{a}}\end{array}$ & $\begin{array}{l}\text { Mean } \mathbf{\pm} \\
\text { SD }^{\mathbf{b}}\end{array}$ & ${\text { Impact, } \mathbf{n}(\%)^{\mathbf{b}, \mathbf{c}}}$ \\
\hline Functional limitation & $0.3 \pm 0.8$ & $27(4.2)$ \\
Physical pain & $0.8 \pm 1.4$ & $77(12.0)$ \\
Psychological discomfort & $0.5 \pm 1.2$ & $44(6.9)$ \\
Physical disability & $0.3 \pm 0.9$ & $28(4.4)$ \\
Psychological disability & $0.3 \pm 0.9$ & $23(3.6)$ \\
Social disability & $0.2 \pm 0.7$ & $19(3.0)$ \\
Handicap & $0.2 \pm 0.7$ & $18(2.8)$ \\
OHIP-NLI4 total score & $2.5 \pm 5.2$ & $122(19.1)$ \\
\hline
\end{tabular}

Notes: Data are presented as mean \pm SD or $n(\%)$. ${ }^{a}$ Subdomains according to Slade. ${ }^{33}$ based on 640 participants that have filled in the OHIP-NLI4 questionnaire completely. Partially completed and empty questionnaires were omitted from the analysis. 'For the OHIP-NLI4, an impact is defined as a response of at least "occasionally" within the specific subdomain.

a dentist, compared to $2.3 \pm 5.0$ in those with a dentist $(p=0.029)$. Patients without regular dentist consultation had a mean score of $3.7 \pm 7.0$, compared to $2.1 \pm 4.6$ in subjects who regularly visit a dentist $(p=0.002)$ (Table S1).

As illustrated in Figure 2, patients with an impact in oral health-related QoL also demonstrated impaired general health-related QoL, indicated by significantly lower scores for all SF-36 concept scales, compared to individuals without an impact in oral health-related QoL. When we compared our data with data from the general population of the Netherlands and a subgroup of inhabitants of the city of Amsterdam, ${ }^{30}$ we observed that patients with an impact in oral health-related QoL had significantly lower SF-36 scores, while patients with no impact in oral health-related QoL demonstrated similar scores (the scores are tabulated in Table S2).

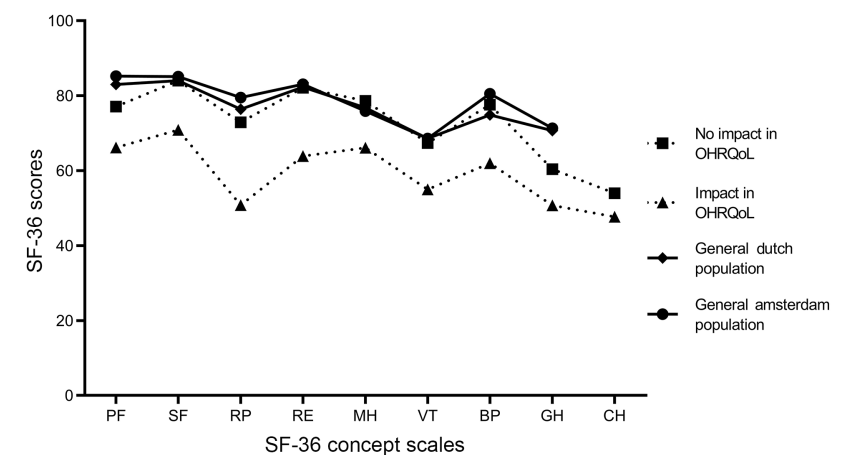

Figure 2 General health-related QoL and oral health-related QoL. The general health-related QoL profile of patients from the current study with and without an impact in oral health-related QoL (defined as a response of at least "occasionally" within at least one OHIP-NLI4 subdomain). As reference, the general population of the Netherlands and general Amsterdam population have been added to the figure. ${ }^{30}$ Abbreviations: PF, physical functioning; SF, social functioning; RP, role limitations due to physical health problems; RE, role limitations due to emotional problems; BP, bodily pain; $\mathrm{GH}$, general health perceptions; VT, vitality; $\mathrm{MH}$, mental health; $\mathrm{CH}$, changes in health over time.

\section{Discussion}

This study aimed to provide insight into dental care utilization and the extent of perceived oral health problems of patients with T2DM at family physician offices. Dental care utilization included having a dentist, going to the dentist at least once a year, and having dental insurance coverage. In the current study, $76 \%$ of all patients reported visiting the dentist at least once a year. The finding that this decreased with older age is similar to recent observations in the general Dutch population, where $84 \%$ of individuals aged 45-65 years visited the dentist at least once a year, decreasing to $63 \%$ for those older than 65 years. ${ }^{34}$ Furthermore, $69 \%$ of the subjects in the present study had dental insurance, which is only slightly less 
Table 6 Oral health problems and oral health-related QoL $(n=640)$



Notes: Data are presented as mean $\pm S D$ or $n(\%)$. Mann-Whitney $U$ and chi-square tests were used to analyze differences between patients with and without selfreported oral health problems regarding OHIP-NLI4 severity scores and impact, respectively. ${ }^{a}$ For the OHIP-NLI4, an impact is defined as a response of at least "occasionally" within the specific subdomain. 'Based on 495 participants for whom the periodontitis screening tool could be applied, and who had also filled in the OHIP-NLI4 questionnaire completely. Partially completed and empty questionnaires were omitted from the analysis. 'Based on 634 participants of whom it was known whether they were edentulous or not, and who had also filled in the OHIP$\mathrm{NL} 14$ questionnaire completely. Partially completed and empty questionnaires were omitted from the analysis. ${ }^{*} p<0.05,{ }^{*} p<0.01$, $* * * p<0.001$

compared to the national average of $72 \%$ in $2016 .{ }^{35}$ Our finding that patients with T2DM do not differ much from the general population regarding dental care utilization is not in agreement with studies from the USA. In these studies, it was demonstrated that patients with DM were less likely to visit a dentist regularly ${ }^{16-19}$ and that fewer patients with DM had dental insurance coverage. ${ }^{18}$ One explanation for this discrepancy could be the fact that patients without an understanding of spoken and written Dutch were excluded for the current study. This could leave out important minorities with low dental care utilization, while minorities were included in the studies from the USA. Nevertheless, since individuals with T2DM are considered at higher risk for oral complications, ${ }^{9}$ there is room for improvement with a quarter not visiting the dentist at least once a year. The results suggest that certain subgroups of patients with T2DM might demand extra motivation to visit the dentist, such as edentulous subjects. These subjects were less likely to see the necessity of visiting a dentist since they lost their teeth. However, research suggests that edentulous patients with DM have an increased risk for opportunistic candida-related infections underneath their denture, such as denture stomatitis, ${ }^{9,36,37}$ which requires professional treatment. ${ }^{38}$ Dental care utilization was also lower in smokers. There is convincing evidence that smoking cessation results in significant improvement in oral health. ${ }^{39}$ However, if cessation cannot be achieved for whatever reason, smokers should at least be urged to have their oral health regularly monitored by a dentist, considering their increased risk for many oral diseases. ${ }^{39}$ In contrary to previous research, ${ }^{18}$ education level and ethnicity were presently not associated with dental care utilization.

Our study shows that perceived oral health problems are relatively common in patients with T2DM at the Dutch family physician offices. In sum, $82 \%$ of all subjects of the current study population was suffering from at least one of the following self-reported oral health problems: pain in the mouth, xerostomia, bad breath and periodontitis. The overall prevalence of periodontitis was especially high. Periodontitis is an inflammatory disease of the supporting structures of the teeth (root cementum, periodontal ligament and alveolar bone), caused by an aberrant host response to bacteria in the dental biofilm. ${ }^{40}$ If the inflammatory response persists, destruction of these structures results in loosening of teeth and ultimately tooth loss. ${ }^{41}$ In the current study, the estimated overall prevalence of periodontitis was $69 \%$. By comparison, a recent study from the USA also showed a high prevalence $(83 \%)$ of periodontitis in older adults with DM (aged $\geq 65$ years). ${ }^{42}$ However, this number also included patients with a mild form of periodontitis, accounting for approximately $5-10 \%$ of the cases, while our screening tool did not take those cases into account. Besides the fact that the prevalence of periodontitis increased with age in our study, periodontitis was also observed more frequently in smokers. This was no surprise since smoking is generally considered as a major modifiable risk factor for the development and progression of periodontitis. $^{43}$ The finding that patients without a dentist were more likely to have periodontitis is supported by research from the USA, where the prevalence of 
periodontitis was significantly higher when patients had not visited the dentist in the past year $(55 \%) .{ }^{44}$

More than one-third of the current study population suffered from xerostomia (35\% of males and $40 \%$ of females). A systematic review of population-based studies on xerostomia showed a wide range in prevalence across all age groups. ${ }^{45}$ From the latter systematic review, when considering those studies $(\mathrm{n}=10)$ with a study population with an age range similar to the current study group, the prevalence was generally lower compared to our T2DM study participants. ${ }^{45}$ The biologic mechanism between the high prevalence of dry mouth in individuals with T2DM is not yet fully elucidated. The relatively older age of patients with T2DM is likely to play a role since the prevalence of oral dryness increases with age. ${ }^{45}$ Xerogenic medication, such as anti-hypertensives or psychotropic drugs (often prescribed to relieve neurologic pain), could be other important risk factors for xerostomia. ${ }^{46,47}$ Subsequently, this could also increase the risk for oral complications that are related to dry mouth, such as oral Candida infections and dental caries. ${ }^{48}$ Therefore, medication use could be an important confounding factor in the association between DM and self-reported oral health and oral health-related QoL. Unfortunately, we have no information about medication use due to the limited access we had to the electronic health record. In the current study, smokers and patients with obesity were more likely to suffer from xerostomia, which is in agreement with the literature. A 15-year longitudinal study from Sweden also showed an association between smoking and xerostomia, ${ }^{49}$ and high BMI was also associated with a reduction in salivary flow in previous research. ${ }^{50}$ Our finding that an increased risk score for diabetic foot (Simm's 1, 2 or 3) was associated with xerostomia is also interesting. An integral part of the Simm's score is the Semmes-Weinstein monofilament examination, which tests loss of sensibility and is therefore often used as a screening tool for peripheral diabetic neuropathy. ${ }^{51}$ It is conceivable that the perception of oral dryness could be a symptom of diabetic neuropathy. Another study has also suggested an association between dry mouth and diabetic neuropathy in patients with DM. ${ }^{52}$

Pain in the mouth and bad breath were reported less frequently, with $15 \%$ and $12 \%$ of the study population, respectively. Moreover, the figures about bad breath should be interpreted with caution, as it has been shown that, in many cases, self-reported bad breath does not reflect objective oral malodor (halitosis). ${ }^{53}$
A considerable proportion of the present study population (19\%) had an impaired oral health-related QoL. However, the mean OHIP-NL14 score $(2.5 \pm 5.2)$ was not significantly different compared to the mean score found in a general adult Dutch population (2.8 \pm 5.9$).{ }^{54}$ More than half of our study population also reported a total score of 0 , which shows that there is a large proportion within the T2DM study population that experiences no subjective problems regarding oral health. This is supported by another study, who also did not find differences in oral health-related QoL between patients with DM and nondiabetic subjects. ${ }^{55}$ However, explorative analyses in the present study population revealed several subgroups that need extra attention. For example, oral health-related QoL was more frequently impaired in patients with an ethnicity other than Western-European (mainly patients from Surinam, Indonesia, Morocco, Turkey and the Netherlands Antilles). This is in agreement with previous research from the USA, where adults from ethnic minorities also demonstrated worse oral health-related QoL. ${ }^{56}$ Smoking was also associated with impaired oral healthrelated QoL, which is in agreement with the literature. ${ }^{57}$ Patients with low dental care utilization (ie, those without a dentist and/or not regularly visiting one) also demonstrated worse oral health-related QoL. A Swedish study showed similar results in elderly subjects, where long-term routine dental attendance positively affected oral healthrelated QoL. ${ }^{58}$ Interestingly, impaired oral health-related QoL coincided with lower general health-related QoL in our study (Figure 2 and Table S2). Furthermore, also compared to the general population from the Netherlands and Amsterdam, general health-related QoL was significantly lower for each concept scale within the group of patients with an impaired oral health-related QoL. However, the group without an impaired oral healthrelated QoL had comparable or even higher SF-36 concept scores than the general population from the Netherlands and Amsterdam (except for "physical functioning" and "general health perceptions"; Figure 2 and Table S2). Previous research also showed that part of the variance of general health-related QoL (approximately 10\%) could be explained by oral health-related QoL. ${ }^{59}$

This present report has several strengths and limitations. This is the first study that investigated dental care utilization and the extent of perceived oral health problems in patients with $\mathrm{T} 2 \mathrm{DM}$ attending primary care in the Netherlands. This knowledge will be important for further implementation of oral health in primary diabetes care as 
recommended in the care guidelines. ${ }^{7,13-15}$ Another strength of this study was the fact that patients were recruited at 24 family physician offices throughout the area of Amsterdam, the Netherlands. This large number of offices increases the generalizability of the results for the general population in the Netherlands. This is further supported by Figure 2, demonstrating that the general health-related QoL profile of the current study population is comparable to that of the general Dutch population. Nonetheless, a vulnerable group of potential patients might have been missed due to the language requirements (understanding spoken and written Dutch), potentially resulting in underestimation of the extent of problems related to oral health in the overall T2DM population. The current results might be less generalizable to other parts in the world, as many aspects investigated are region and culture dependent, such as local diabetes care and oral health care delivery, insurance systems and oral hygiene habits. This underlines the importance to investigate selfreported oral health and QoL in diabetic populations in other countries as well. Notably, the methods to assess QoL used in the current study are internationally validated and available in multiple languages. The cross-sectional design of this study prevents us from establishing causal associations between certain patient characteristics and problems with oral health within patients with DM. However, the aim of this study was to obtain overall insight into the extent of perceived oral health problems in patients with DM, rather than assessing the etiology. Another limitation was the fact that dental care utilization was self-reported. Patients might have been tempted to provide socially desirable answers. For example, some individuals could have reported that they visited the dentist at least once a year, while in reality, they did not. Therefore, social desirability bias cannot be ruled out. There could also be a role for memory bias since it can be difficult to remember exactly the last time one has visited the dentist. Both can result in overestimation of dental care utilization. Also, the exact question about dental care utilization was only about dentist visits, while dental hygienists were not mentioned. As a result, on the one hand, some patients might have reported a visit to the dentist, while in reality, they visited a dental hygienist. On the other hand, some patients might have visited a dental hygienist, and thereby maintained good oral health, while they reported low dental care utilization (ie, did not visit a dentist once a year). This confusing overlap could obscure the differences between subjects who - according to our question about dentist visit - do or do not visit a dentist once a year. Finally, the prevalence of periodontitis was estimated using a screening tool, based on selfreported items and demographics. This will inevitably lead to some misclassification. However, the accuracy of this screening tool was considered good (Area Under the ROC Curve: 0.88$)^{28}$ and moreover, our prevalence figures are similar to those found in other epidemiological studies investigating patients with $\mathrm{DM}{ }^{42}$

\section{Conclusion}

In conclusion, although the majority of patients with T2DM in primary care reports to have a dentist and to visit a dentist at least once a year, a closer look at the results revealed that certain subgroups will need extra attention. Furthermore, problems regarding oral health are very common in patients with T2DM attending primary care: $82 \%$ had at least one of the investigated self-reported oral health problems (pain in the mouth, xerostomia, bad breath and periodontitis). Oral health-related QoL was impaired in individuals who experience these oral health problems, as well as in smokers, patients with low dental care utilization and subjects with an ethnicity other than Western-European. Finally, impaired oral health-related QoL seemed to coincide with impaired general health-related QoL.

\section{Ethics approval and informed consent}

The study was approved by the medical ethical committee of the Vrije Universiteit Medical Centre (2014.585). The longitudinal study of this project included an intervention where communication between family physicians and dentists was facilitated and promoted. Since this communication flow could not be anonymized, the participants in the experimental-office group were asked to give written informed consent. This was not required for the participants in the control-office group, as no such communication between family physicians and dentists was initiated.

\section{Data availability}

The data supporting the results in the current study are available from the corresponding author on reasonable request.

\section{Abbreviations}

(T2)DM, (type 2) diabetes mellitus; QoL, quality of life; SNOSE, sequentially numbered, opaque sealed envelopes; BMI, body mass index; LDL-C, low-density lipoprotein 
cholesterol; eGFR, estimated glomerular filtration rate; SF-36, 36-item Short Form health survey; OHIP-NL14, Dutch 14-item oral health impact profile survey; ROC, receiver operating characteristic.

\section{Acknowledgments}

We gratefully acknowledge all the participating family physicians and nurse practitioners for their efforts to recruit patients and collect data for this study. We also want to thank Dr.E.W. Meesters for setting up initial contact with many potential family physician offices across the area of Amsterdam. This work is part of the Ph.D. track of MJL Verhulst, which is funded by Sunstar Suisse SA, who had no role in the design of the study and collection, analysis, and interpretation of data and in writing the manuscript. In addition, author BG Loos is partly funded by a grant from the University of Amsterdam for the focal point "oral infection and inflammation".

\section{Author contributions}

All authors contributed to data analysis, drafting or revising the article, gave final approval of the version to be published, and agree to be accountable for all aspects of the work.

\section{Disclosure}

Mr Martijn Verhulst reports grants from Sunstar Suisse SA, during the conduct of the study. Prof. Dr Bruno Loos reports grants from Sunstar Suisse SA, during the conduct of the study; received speaking fees from ACTA Talks, outside of the submitted work. The authors report no other conflicts of interest in this work.

\section{References}

1. Global report on diabetes. World Health Organization; 2016. Available from: http://www.who.int/diabetes/global-report/en/. Accessed on April 24, 2017.

2. Fowler MJ. Microvascular and macrovascular complications of diabetes. Clin Diabetes. 2008;26(2):77-82. doi:10.2337/diaclin.26.2.77

3. Lloyd A, Sawyer W, Hopkinson P. Impact of long-term complications on quality of life in patients with type 2 diabetes not using insulin. Value Health. 2001;4(5):392-400.

4. U.K. Prospective Diabetes Study Group. Quality of life in type 2 diabetic patients is affected by complications but not by intensive policies to improve blood glucose or blood pressure control (UKPDS 37). U. K. prospective diabetes study group. Diabetes Care. 1999;22 (7):1125-1136.

5. Ship JA. Diabetes and oral health: an overview. $J$ Am Dent Assoc. 2003;134:4S-10S.

6. Lamster IB, Lalla E, Borgnakke WS, Taylor GW. The relationship between oral health and diabetes mellitus. J Am Dent Assoc. 2008;139:19S-24S.
7. Sanz M, Ceriello A, Buysschaert M, et al. Scientific evidence on the links between periodontal diseases and diabetes: consensus report and guidelines of the joint workshop on periodontal diseases and diabetes by the international diabetes federation and the European federation of periodontology. Diabetes Res Clin Pract. 2018;137:231-241.

8. D'Aiuto F, Gkranias N, Bhowruth D, et al. Systemic effects of periodontitis treatment in patients with type 2 diabetes: a 12 month, single-centre, investigator-masked, randomised trial. Lancet Diabetes Endocrinol. 2018;6(12):954-965.

9. Verhulst MJL, Loos BG, Gerdes VEA, Teeuw WJ. Evaluating all potential oral complications of diabetes mellitus. Front Endocrinol (Lausanne). 2019;10(56).

10. Durham J, Fraser HM, McCracken GI, Stone KM, John MT, Preshaw PM. Impact of periodontitis on oral health-related quality of life. J Dent. 2013;41(4):370-376. doi:10.1016/j.jdent.2013.01.008

11. Gerdin EW, Einarson S, Jonsson M, Aronsson K, Johansson I. Impact of dry mouth conditions on oral health-related quality of life in older people. Gerodontology. 2005;22(4):219-226.

12. Sandberg GE, Wikblad KF. Oral health and health-related quality of life in type 2 diabetic patients and non-diabetic controls. Acta Odontol Scand. 2003;61(3):141-148.

13. IDF Clinical Guidelines Task Force. IDF Guideline on Oral Health for People with Diabetes. Brussels:: International Diabetes Federation; 2009.

14. American Diabetes Association. Oral Health and Hygiene. 2012; Available from: http://www.diabetes.org/living-with-diabetes/treat ment-and-care/oral-health-and-hygiene/. Accessed November 19, 2018.

15. Rutten G, De Grauw W, Nijpels G, et al. NHG-standaard diabetes mellitus type 2 (derde herziening). Huisarts Wet. 2013;56(10):512-525.

16. Tomar SL, Lester A. Dental and other health care visits among U.S. adults with diabetes. Diabetes Care. 2000;23(10):1505-1510.

17. Chaudhari M, Hubbard R, Reid RJ, et al. Evaluating components of dental care utilization among adults with diabetes and matched controls via hurdle models. BMC Oral Health. 2012;12(1):20. doi:10.1186/1472-6831-12-20

18. Macek MD, Tomar SL. Dental care visits among dentate adults with diabetes and periodontitis. J Public Health Dent. 2009;69 (4):284-289. doi:10.1111/j.1752-7325.2009.00136.x

19. Luo H, Bell RA, Wright W, Wu Q, Wu B. Trends in annual dental visits among US dentate adults with and without self-reported diabetes and prediabetes, 2004-2014. J Am Dent Assoc. 2018;149 (6):460-469. doi:10.1016/j.adaj.2018.01.008

20. Crocombe LA, Broadbent JM, Thomson WM, Brennan DS, Poulton R. Impact of dental visiting trajectory patterns on clinical oral health and oral health-related quality of life. $J$ Public Health Dent. 2012;72(1):36-44. doi:10.1111/j.1752-7325.2011.00281.x

21. Doig GS, Simpson F. Randomization and allocation concealment: a practical guide for researchers. J Crit Care. 2005;20(2):187-191; discussion 191-183. doi:10.1016/j.jcrc.2005.04.005

22. Clinical guidelines on the identification, evaluation, and treatment of overweight and obesity in adults: executive summary. Expert Panel on the Identification, Evaluation, and Treatment of Overweight in Adults. Am J Clin Nutr. 1998;68(4):899-917. doi:10.1093/ajen/68.4.899

23. Chobanian AV, Bakris GL, Black HR, et al. The seventh report of the joint national committee on prevention, detection, evaluation, and treatment of high blood pressure: the JNC 7 report. Jama. 2003;289 (19):2560-2572. doi:10.1001/jama.289.19.2560

24. Nederlands Huisartsen Genootschap. Cardiovasculair risicomanagement (Tweede herziening)[Dutch guideline cardiovascular risk management (Second revision)]. Huisarts Wet. 2012;55:14-28.

25. De Grauw W, Kaasjager H, Bilo H, Faber E, Flikweert S, Gaillard C. Landelijke transmurale afspraak chronische nierschade. Huisarts Wet. 2009;52(12):586-597. doi:10.1007/BF03085802

26. Eke PI, Dye BA, Wei L, et al. Self-reported measures for surveillance of periodontitis. J Dent Res. 2013;92(11):1041-1047. doi:10.1177/ 0022034513505621 
27. Genco RJ, Falkner KL, Grossi S, Dunford R, Trevisan M. Validity of self-reported measures for surveillance of periodontal disease in two western New York population-based studies. J Periodontol. 2007;78 (7S):1439-1454. doi:10.1902/jop.2007.060435

28. Verhulst MJL, Teeuw WJ, Bizzarro S, et al. A rapid, non-invasive tool for periodontitis screening in a medical care setting. BMC Oral Health. In press.

29. Page RC, Eke PI. Case definitions for use in population-based surveillance of periodontitis. J Periodontol. 2007;78(7S):1387-1399.

30. Aaronson NK, Muller M, Cohen PD, et al. Translation, validation, and norming of the Dutch language version of the SF-36 Health Survey in community and chronic disease populations. J Clin Epidemiol. 1998;51(11):1055-1068.

31. Ware JE Jr., Sherbourne CD, The MOS. 36-item short-form health survey (SF-36). I. Conceptual framework and item selection. Med Care. 1992;30(6):473-483.

32. van der Meulen MJ, John MT, Naeije M, Lobbezoo F. The Dutch version of the Oral Health Impact Profile (OHIP-NL): translation, reliability and construct validity. BMC Oral Health. 2008;8:11.

33. Slade GD. Derivation and validation of a short-form oral health impact profile. Community Dent Oral Epidemiol. 1997;25(4):284-290.

34. Centraal Bureau voor de Statistiek (CBS). Gezondheid en zorggebruik 2016-2017. Available from: https://opendata.cbs.nl/statline/\#/CBS/nl/data set/83384NED/table?dl=12B68. Accessed October 25, 2018.

35. Nederlandse Zorgautoriteit (NZa). Marktscan Zorgverzekeringsmarkt 2016. Available from: https://puc.overheid.nl/nza/doc/PUC_3484_22/ 1/. Accessed October 25, 2018.

36. Dorocka-Bobkowska B, Budtz-Jörgensen E, WłSoch S. Non-insulin dependent diabetes mellitus as a risk factor for denture stomatitis J Oral Pathol Med. 1996;25(8):411-415.

37. Dorocka-Bobkowska B, Zozulinska-Ziolkiewicz D, WieruszWysocka B, Hedzelek W, Szumala-Kakol A, Budtz-Jorgensen E. Candida-associated denture stomatitis in type 2 diabetes mellitus. Diabetes Res Clin Pract. 2010;90(1):81-86.

38. Petersen PE, Yamamoto T. Improving the oral health of older people: the approach of the WHO global oral health programme. Community Dent Oral Epidemiol. 2005;33(2):81-92.

39. Warnakulasuriya S, Dietrich T, Bornstein MM, et al. Oral health risks of tobacco use and effects of cessation. Int Dent J. 2010;60(1):7-30

40. Bartold PM, Van Dyke TE. An appraisal of the role of specific bacteria in the initial pathogenesis of periodontitis. $J$ Clin Periodontol. 2019;46(1):6-11.

41. Pihlstrom BL, Michalowicz BS, Johnson NW. Periodontal diseases. Lancet. 2005;366(9499):1809-1820.

42. Eke PI, Wei L, Borgnakke WS, et al. Periodontitis prevalence in adults $\geq 65$ years of age, in the USA. Periodontol 2000. 2016;72 (1):76-95.

43. Genco RJ, Borgnakke WS. Risk factors for periodontal disease. Periodontol 2000. 2013;62(1):59-94.
44. Eke PI, Thornton-Evans GO, Wei L, Borgnakke WS, Dye BA, Genco RJ. Periodontitis in US Adults. J Am Dent Assoc. 2018;149 (7):576-588.e576.

45. Orellana MF, Lagravère MO, Boychuk DG, Major PW, Flores-Mir C, Ortho C. Prevalence of Xerostomia in population-based samples: a systematic review. J Public Health Dent. 2006;66(2):152-158.

46. Scully C. Drug effects on salivary glands: dry mouth. Oral Dis. 2003;9(4):165-176.

47. Sreebny LM, Schwartz SS. A reference guide to drugs and dry mouth-2nd edition. Gerodontology. 1997;14(1):33-47.

48. Fratto G, Manzon L. Use of psychotropic drugs and associated dental diseases. Int J Psychiat Med. 2014;48(3):185-197.

49. Johansson AK, Johansson A, Unell L, Ekback G, Ordell S, Carlsson GE. A 15-yr longitudinal study of xerostomia in a Swedish population of 50-yr-old subjects. Eur J Oral Sci. 2009;117(1):13-19.

50. Flink H, Bergdahl M, Tegelberg A, Rosenblad A, Lagerlof F. Prevalence of hyposalivation in relation to general health, body mass index and remaining teeth in different age groups of adults. Community Dent Oral Epidemiol. 2008;36(6):523-531.

51. Feng Y, Schlösser FJ, Sumpio BE. The Semmes Weinstein monofilament examination as a screening tool for diabetic peripheral neuropathy. J Vasc Surg. 2009;50(3):675-682.e671.

52. Borgnakke WS, Anderson PF, Shannon C, Jivanescu A. Is there a relationship between oral health and diabetic neuropathy? Curr Diab Rep. 2015;15(11):93.

53. Bornstein MM, Kislig K, Hoti BB, Seemann R, Lussi A. Prevalence of halitosis in the population of the city of Bern, Switzerland. Eur J Oral Sci. 2009;117(3):261-267.

54. Verrips G, Schuller A. Subjective Oral Health in Dutch Adults. Dent J. 2013;1(2):12.

55. Allen EM, Ziada HM, O'Halloran D, Clerehugh V, Allen PF. Attitudes, awareness and oral health-related quality of life in patients with diabetes. J Oral Rehabil. 2008;35(3):218-223.

56. Huang DL, Park M. Socioeconomic and racial/ethnic oral health disparities among US older adults: oral health quality of life and dentition. J Public Health Dent. 2015;75(2):85-92.

57. Maida CA, Marcus M, Spolsky VW, Wang Y, Liu H. Sociobehavioral predictors of self-reported oral health-related quality of life. Qual Life Res. 2013;22(3):559-566.

58. Åstrøm AN, Ekback G, Ordell S, Nasir E. Long-term routine dental attendance: influence on tooth loss and oral health-related quality of life in Swedish older adults. Community Dent Oral Epidemiol. 2014;42(5):460-469.

59. Zimmer S, Bergmann N, Gabrun E, Barthel C, Raab W, Ruffer JU. Association between oral health-related and general health-related quality of life in subjects attending dental offices in Germany. J Public Health Dent. 2010;70(2):167-170. 


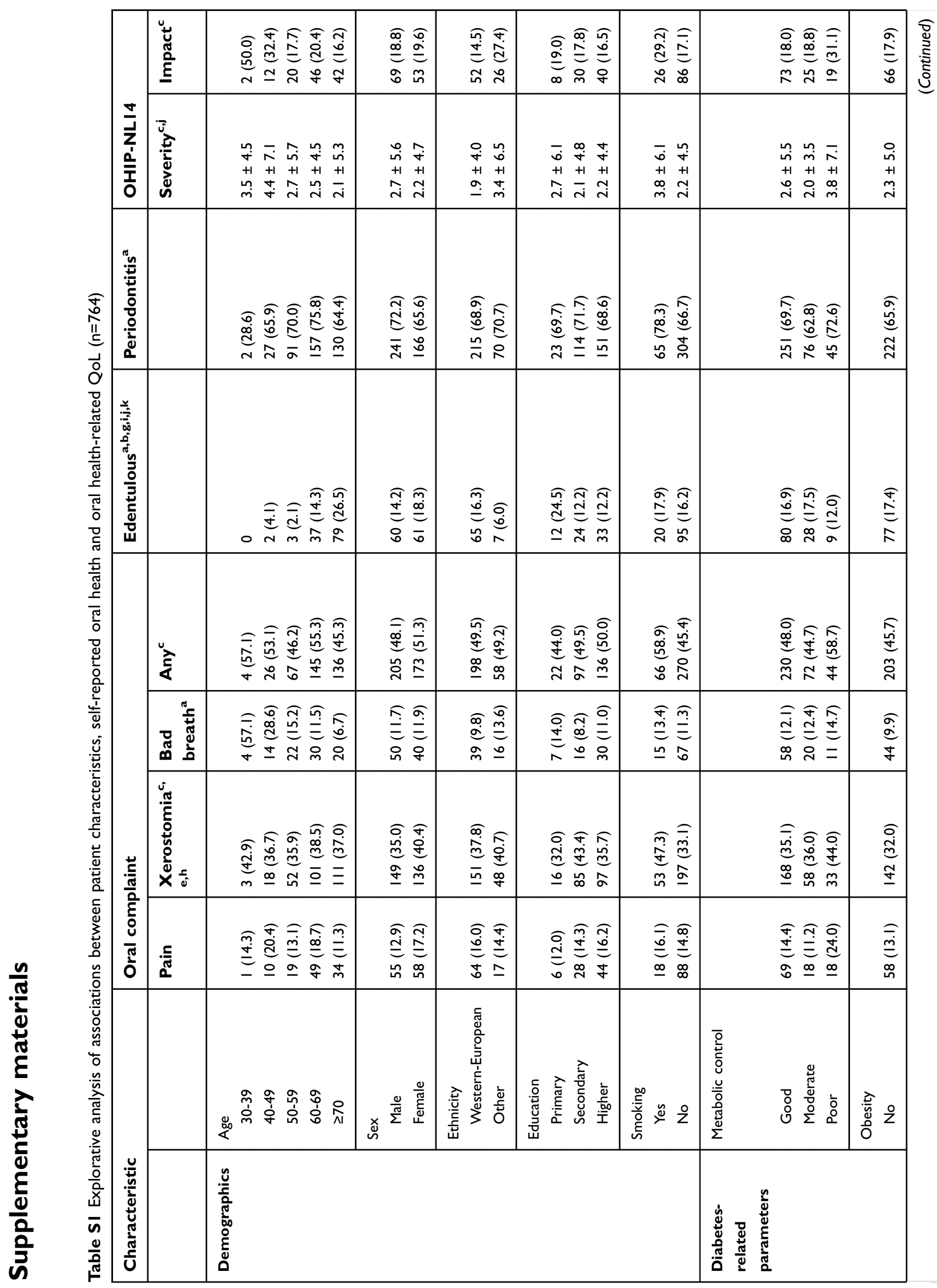




\begin{tabular}{|c|c|c|c|c|c|c|c|c|c|c|c|c|}
\hline & $\begin{array}{l}\stackrel{u}{\breve{g}} \\
\underline{\underline{g}} \\
\underline{\underline{g}}\end{array}$ & $\begin{array}{l}\underset{m}{d} \\
\underset{n}{n}\end{array}$ & 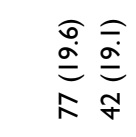 &  & 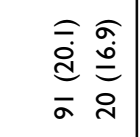 & 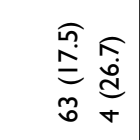 & $\begin{array}{ll}\sigma & \widehat{n} \\
\infty & 0 \\
= & 0 \\
\bar{N} & \bar{m}\end{array}$ & &  &  & 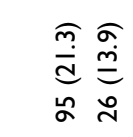 & 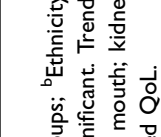 \\
\hline $\begin{array}{l}\bar{z} \\
z \\
\vdots \\
\underline{1} \\
\bar{T} \\
0\end{array}$ & 离 & $\begin{array}{l}\hat{n} \\
+1 \\
\infty \\
\infty \\
i\end{array}$ & 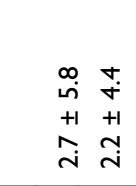 & $\begin{array}{ll}0 & \infty \\
i & 0 \\
+1 \\
+1 & +1 \\
+ & \stackrel{+}{i}\end{array}$ &  & $\begin{array}{ll}\underset{n}{n} & \bar{m} \\
+1 & ++1 \\
& +1 \\
& \stackrel{+}{i}\end{array}$ & $\begin{array}{ll}\bar{n} & \stackrel{a}{n} \\
+1 & ++1 \\
\stackrel{+}{N} & \stackrel{\sim}{N}\end{array}$ & &  & $\begin{array}{ll}0 & 0 \\
\dot{T} \\
+1 & \stackrel{+1}{+1} \\
\bar{i} & \stackrel{m}{m}\end{array}$ &  & 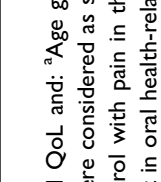 \\
\hline  & & 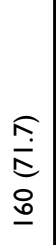 & 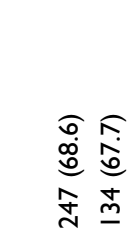 &  &  & 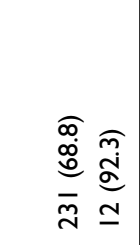 & \begin{tabular}{ll}
$\sigma$ & \\
$\infty$ & $\sigma$ \\
0 & $\sigma$ \\
0 & 0 \\
\multirow{+}{*}{} & $a$
\end{tabular} & & 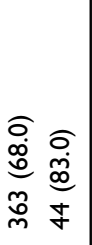 & 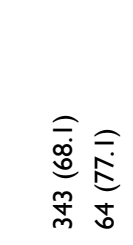 & 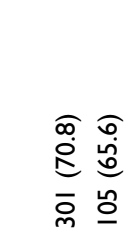 &  \\
\hline  & & 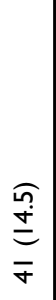 & 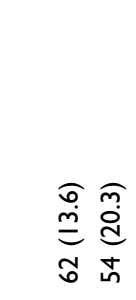 & 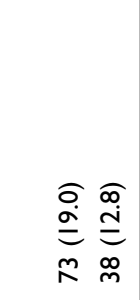 & 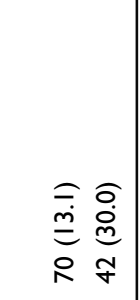 &  &  & & 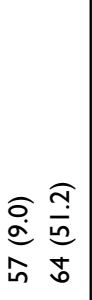 & 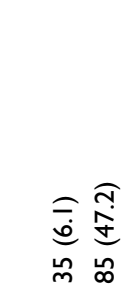 & 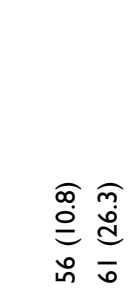 & 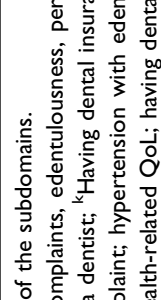 \\
\hline \multirow{4}{*}{ 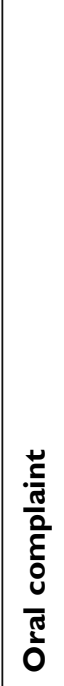 } & 遄 & $\begin{array}{l}\text { m } \\
\tilde{n} \\
\underline{n} \\
\underline{n}\end{array}$ & 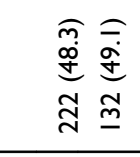 & 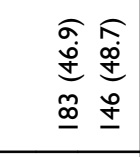 &  & 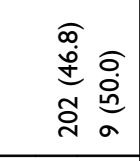 &  & & 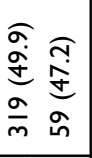 &  & 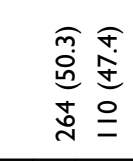 &  \\
\hline & 胥 & 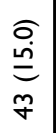 &  & 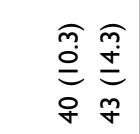 & 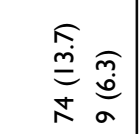 & 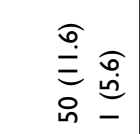 & 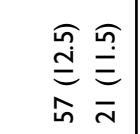 & & 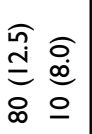 & 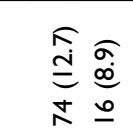 &  & 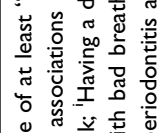 \\
\hline & 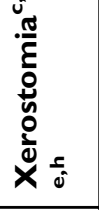 & $\begin{array}{l}\widetilde{\Omega} \\
\mathbb{I} \\
\text { I } \\
\text { I }\end{array}$ & 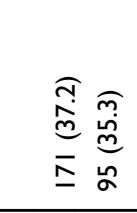 &  & 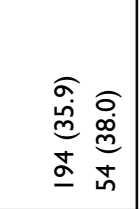 &  & 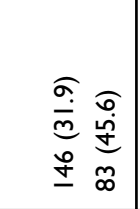 & & 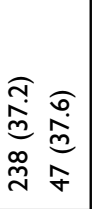 & 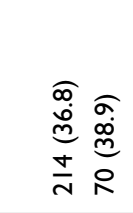 & 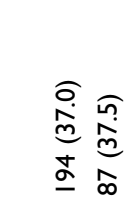 & 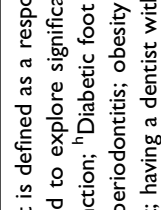 \\
\hline & 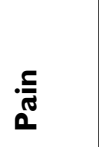 & $\begin{array}{l}\stackrel{0}{\infty} \\
\stackrel{5}{=} \\
\bar{n}\end{array}$ & 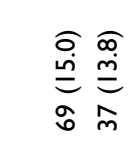 & 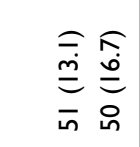 &  &  & 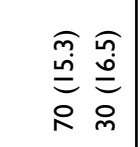 & & 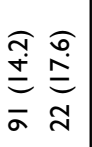 & 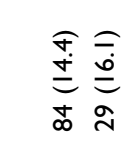 & 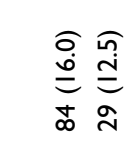 & 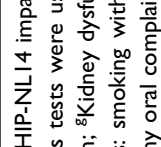 \\
\hline \multirow[b]{2}{*}{ 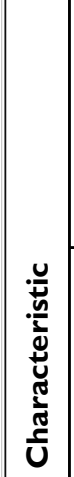 } & & $\underbrace{\stackrel{y}{u}}_{\check{\nu}}$ & 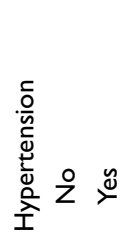 & 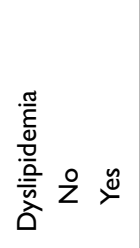 & 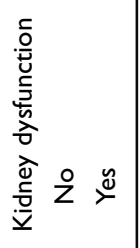 & 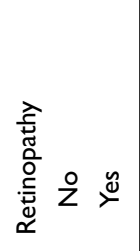 & 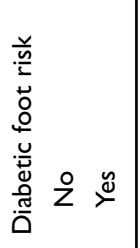 & 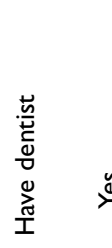 &  &  & 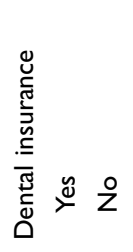 & 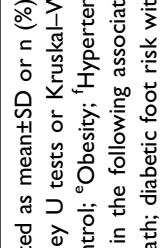 \\
\hline & & & & & & & & \multicolumn{4}{|l|}{ 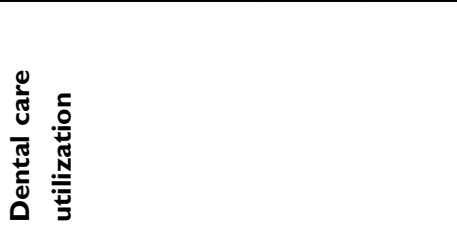 } & 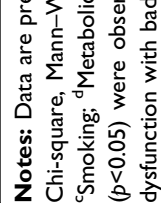 \\
\hline
\end{tabular}


Table S2 General health-related QoL in patients with and without an impact in oral health-related QoL ( $\mathrm{n}=499)$, compared to the general Dutch population

\begin{tabular}{|c|c|c|c|c|}
\hline \multirow[t]{2}{*}{ SF-36 concept scales } & \multicolumn{2}{|c|}{ Impact in OHIP-NLI4 } & \multicolumn{2}{|c|}{ General population $^{a}$} \\
\hline & $\begin{array}{l}\text { Yes } \\
(n=97)\end{array}$ & $\begin{array}{l}\text { No } \\
(n=402)\end{array}$ & $\begin{array}{l}\text { The Netherlands } \\
(n=I, 742)\end{array}$ & $\begin{array}{l}\text { Amsterdam } \\
(n=4,172)\end{array}$ \\
\hline Physical functioning & $66.2 \pm 21.9^{c, d, e}$ & $77.1 \pm 23.4^{\mathrm{b}, \mathrm{d}, \mathrm{e}}$ & $83.0 \pm 22.8^{\mathrm{a}, \mathrm{b}}$ & $85.2 \pm 23.1^{\mathrm{b}, \mathrm{c}}$ \\
\hline Social functioning & $70.9 \pm 22.7^{c, d, e}$ & $84.0 \pm 20.2^{b}$ & $84.0 \pm 22.4^{\mathrm{b}}$ & $85.1 \pm 21.5^{b}$ \\
\hline Role limitations due to physical health problems & $50.8 \pm 4 I . I^{\mathrm{c}, \mathrm{d}, \mathrm{e}}$ & $72.9 \pm 38.7^{\mathrm{c}, \mathrm{e}}$ & $76.4 \pm 36.3^{b}$ & $79.5 \pm 35.4^{\mathrm{b}, \mathrm{c}}$ \\
\hline Role limitations due to emotional problems & $63.9 \pm 41.6^{\mathrm{c}, \mathrm{d}, \mathrm{e}}$ & $82.1 \pm 33.5^{b}$ & $82.3 \pm 32.9^{\mathrm{b}}$ & $83.1 \pm 32.7^{\mathrm{b}}$ \\
\hline General mental health & $66.1 \pm 18.9^{c, d, e}$ & $78.6 \pm 17.2^{\mathrm{b}, \mathrm{d}, \mathrm{e}}$ & $76.8 \pm 17.4^{\mathrm{b}, \mathrm{c}}$ & $75.9 \pm 17.6^{\mathrm{b}, \mathrm{c}}$ \\
\hline Vitality & $55.0 \pm 19.0^{c, d, e}$ & $67.4 \pm 18.9^{b}$ & $68.6 \pm 19.3^{b}$ & $68.6 \pm 19.2^{b}$ \\
\hline Bodily pain & $62.0 \pm 25.4^{\mathrm{c}, \mathrm{d}, \mathrm{e}}$ & $77.6 \pm 22.7^{\mathrm{b}, \mathrm{d}, \mathrm{e}}$ & $74.9 \pm 23.4^{\mathrm{b}, \mathrm{c}}$ & $80.5 \pm 24.4^{\mathrm{b}, \mathrm{c}}$ \\
\hline General health perceptions & $50.6 \pm 20.1^{\mathrm{c}, \mathrm{d}, \mathrm{e}}$ & $60.4 \pm 18.0^{\mathrm{b}, \mathrm{d}, \mathrm{e}}$ & $70.7 \pm 20.7^{\mathrm{b}, \mathrm{c}}$ & $71.3 \pm 20.8^{\mathrm{b}, \mathrm{c}}$ \\
\hline Changes in health over time & $47.7 \pm 20.4^{c}$ & $54.0 \pm 18.9^{b}$ & $\mathrm{n} / \mathrm{a}$ & $\mathrm{n} / \mathrm{a}$ \\
\hline
\end{tabular}

Notes: Data are presented as mean \pm SD. Concept scales according to Ware et al. ${ }^{31}$ Comparisons of SF-36 concept scales scores between patients with and without an impact in OHIP-NLI4 were analyzed using Mann-Whitney $U$ tests. Comparisons of the SF-36 concept scale scores between the present study population (divided for this analysis in groups with or without an impact in OHIP-NLI4) and the general Dutch population were performed by one-sample t-tests. $p$-values <0.05 were considered significant. ${ }^{\mathrm{a}}$ General health-related $\mathrm{QoL}$ in the general population from the Netherlands and Amsterdam, according to data from Aaronson et al ${ }^{30}$; ${ }^{b}$ significantly different from patients with an impact in OHIP-NLI4, included in the present study; 'significantly different from patients without an impact in OHIP-NLI4, included in the present study; ${ }^{d}$ significantly different from the general population from the Netherlands; ${ }^{\text {e }}$ significantly different from the general population from Amsterdam.

Table S3 Self-reported oral health questions

\begin{tabular}{|l|l|}
\hline Question & Questions and Dutch translations (italic) \\
\hline I. & $\begin{array}{l}\text { Do you have a regular dentist? } \\
\text { Heeft u een vaste tandarts? } \\
\text { Do you visit your dentist regularly? (at least once or twice a year) } \\
\text { Bezoekt u uw tandarts regelmatig? (minimaal I a 2 keer per jaar) } \\
\text { Do you have dental insurance? } \\
\text { Heeft u een tandartsverzekering? } \\
\text { How many teeth do you have? } \\
\text { H. }\end{array}$ \\
$\begin{array}{ll}\text { Hoeveel eigen tanden enlof kiezen heeft u? } \\
\text { Do you have a partial or full denture? } \\
\text { Heeft u een gedeeltelijke/dan wel volledige gebitsprothese? } \\
\text { Do you sometimes suffer from: } \\
\end{array}$ & $\begin{array}{l}\text { a) Pain in your mouth? } \\
\text { b) A dry mouth? } \\
\text { c) Bad breath? } \\
\text { Heeft u wel eens last van): } \\
\text { a) Pijn in uw mond } \\
\text { b) Een droge mond? } \\
\text { c) Een slechte adem? }\end{array}$ \\
\hline
\end{tabular}


Table S4 Self-reported oral health questions (periodontitis-related questions)

\begin{tabular}{|l|l|}
\hline Question & Questions and Dutch translations (italic) \\
\hline I. & $\begin{array}{l}\text { Do you think you might have gum disease? } \\
\text { Denkt u dat u een tandvleesaandoening heeft, ook wel gingivitis of parodontitis genoemd? } \\
\text { Overall, how would you rate the health of your teeth and gums? } \\
\text { Hoe zou u over het algemeen genomen de gezondheid van uw tanden en tandvlees beoordelen? } \\
\text { Have you ever had treatment for gum disease such as scaling and root planing, sometimes called "deep cleaning"? } \\
\text { Bent u wel eens voor een tandvleesaandoening behandeld, soms ook wel "diep schoonmaken" of "pocket behandeling" genoemd? } \\
\text { Have you ever had any teeth become loose on their own, without an injury? } \\
\text { Heeft u wel eens last van losstaande tanden gehad, zonder dat daar een ongeluk of trauma aan vooraf ging? } \\
\text { Have you ever been told by a dental professional that you lost bone around your teeth? } \\
\text { Heeft een tandheelkundige specialist u wel eens verteld dat u botverlies heeft rondom uw tanden? } \\
\text { During the past } 3 \text { months, have you noticed a tooth that doesn't look right? } \\
\text { Heeft u de afgelopen drie maanden wel eens gemerkt dat een tand er niet goed uit zag? } \\
\text { Aside from brushing your teeth with a toothbrush, in the last } 7 \text { days, how many times did you use dental floss or any other device to } \\
\text { clean between your teeth? } \\
\text { Hoe vaak heeft u de laatste zeven dagen, afgezien van tandenpoetsen met een normale tandenborstel, geflost of op een andere manier tussen } \\
\text { uw tanden schoongemaakt? } \\
\text { Aside from brushing your teeth with a toothbrush, in the last } 7 \text { days, how many times did you use mouthwash or other dental rinse } \\
\text { product that you use to treat dental disease or dental problems? } \\
\text { Hoe vaak heeft u de laatste zeven dagen, afgezien van tandenpoetsen met een normale tandenborstel, mondspoelmiddel of een ander } \\
\text { spoelproduct gebruikt om tandheelkundige ziekte of klachten te behandelen? }\end{array}$ \\
\hline
\end{tabular}

Notes: This table presents the original, periodontitis-related self-reported oral health questions from the USA ${ }^{26}$, together with their Dutch translations. ${ }^{28}$

\section{Publish your work in this journal}

Diabetes, Metabolic Syndrome and Obesity: Targets and Therapy is an international, peer-reviewed open-access journal committed to the rapid publication of the latest laboratory and clinical findings in the fields of diabetes, metabolic syndrome and obesity research. Original research, review, case reports, hypothesis formation, expert opinion and commentaries are all considered for publication. The manuscript management system is completely online and includes a very quick and fair peer-review system, which is all easy to use. Visit http://www.dovepress.com/testimonials.php to read real quotes from published authors. 